\title{
An Assessment of Body Composition and Lifestyle in Children Aged from 8 to 10 years
}

Laura Piombino ${ }^{1}$, Antonietta Messina ${ }^{1}$, Luca Piombino ${ }^{2}$, Vincenzo Monda ${ }^{1}$, Fiorenzo Moscatelli ${ }^{3}$, Anna A. Valenzano ${ }^{3}$, Teresa Esposito ${ }^{1}$, Giuseppe Monda ${ }^{1}$, Giuseppe Cibelli ${ }^{3}$, Giovanni Messina ${ }^{1,3}$ and Marcellino Monda ${ }^{1^{*}}$

${ }^{1}$ Department of Experimental Medicine, Section of Human Physiology and Unit of Dietetic and Sport Medicine, Second University of Naples, 16 Costantinopoli Str., 80138 Naples, Italy

${ }^{2}$ Unit of Plastic and Maxillofacial Surgery, Bambino Gesu - Children's Hospital, Rome

${ }^{3}$ Department of Clinical and Experimental Medicine, University of Foggia, Italy

*Corresponding author: Marcellino Monda, MD, Department of Experimental Medicine, Section of Human Physiology and Unit of Dietetic and Sport Medicine, Second University of Naples, Via Costantinopoli 16, 80138 Naples, Italy, Tel: +39 +81566 5804; Fax: +39 +81 5665841; E-mail: marcellino.monda@unina2.it

Received date: March 01, 2016; Accepted date: April 15, 2016; Published date: April 18, 2016

Copyright: ( 2016 Piombino L, et al. This is an open-access article distributed under the terms of the Creative Commons Attribution License, which permits unrestricted use, distribution and reproduction in any medium, provided the original author and source are credited.

\begin{abstract}
Introduction: The high prevalence of childhood obesity is a public health problem across the world, because it is a risk factor for cardiovascular disease, hypertension, hyperlipidemia and insulin resistance. The aim of this study was to investigate the lifestyle, body composition, and to detect any possible behavioral effects and potential repercussions on the body in children.
\end{abstract}

Methods: 272 children of two primary schools underwent bioimpedence analysis (BIA) to assess their body composition. Information was also collects about their eating habits, exercise and lifestyle, by means of a questionnaire administered.

Results: The $19 \%$ of children were obese and $32 \%$ overweight. In the first group, the fat mass constituted $48 \%$ of body weight, while in the second $40 \%$. The $52 \%$ of females and $64 \%$ of males took part in sports $2-3$ times a week. At lunch, pasta was the predominant food, mainly with sauce or vegetables, and $63 \%$ had a second dish as well. For evening dinner, a main course was the predominant food $95 \%$ and was eaten with bread in $61 \%$ of cases. The $18 \%$ of children did not eat green vegetables, and $61 \%$ did not eat fruit. The average daily intake of bread amounted to $80 \mathrm{~g}$ and that of water to 1 liter.

Discussion: The BMI calculated were in line with those reported in 2014 by the Italian Ministry of Health. The BIA revealed high fat mass, probably correlated to a greater differentiation of the cells into adipocytes, which occurs when excessive food intake happens during the growth phase.

Keywords: Obesity; Body composition; Children; Lifestyle

\section{Introduction and Objectives}

Obesity is a complex disorder characterized by an excess of body fat, usually caused by a lack of balance between energy intake and expenditure $[1,2]$. The World Health Organization has estimated that in 2014, more than 1.9 billion adults were overweight, 600 million of which were obese, and that in 2013, 42 million children under 5 years of age were overweight or obese [3].

The high prevalence of childhood obesity is a public health problem across the world, because it is a risk factor for cardiovascular disease, hypertension, hyperlipidemia and insulin resistance [4-6]. A higher incidence of atopy has also been observed, due to an increase in total IgE, as well as psychological disorders such as anxiety and loss of selfesteem, associated with a low body image, parent distress and being teased at school [6-9]. In order to understand the etiology of overweight and obese children and related disorders, and to develop a tailored primary prevention program, in 2007-2008 the IDEFICS began in Europe (Identification and prevention of dietary- and lifestyle induced health effects in children and infants). This was a prospective cohort study with an integrated intervention study that involved 16,224 children aged from 2 to 9 years in eight countries (Cyprus, Belgium, Estonia, Germany, Italy, Spain, Sweden and Hungary) [10]. The prevalence of obesity and fatness is higher in populations from southern Europe (Italy, Cyprus and Spain) and groups with lower levels of education and incomes, in which there is a higher intake of unhealthy foods [11,12]. Children's preference for fatty foods and sweets, sugary drinks, low consumption of fruit and vegetables and physical inactivity were found to be the principle obesogenic factors $[13,14]$. Most children, especially in countries with a higher incidence of childhood obesity (Italy and Cyprus), did not undertake enough physical activity, which should be at least 1 hour per day [15]. Even the building environment of the neighborhood in which they were living had an effect on their movements. Physical activity is favored by the availability of public open spaces, maintenance of roads and buildings and by efficient public transport [16].

In Italy, eating habits have changed over the last fifty years: the consumption of fruit, vegetables, legumes, whole grains and extra virgin olive oil has decreased, whilst that of energy-dense, sugary foods, salt and added fats has increased [17]. In 2007, the Italian 
Ministry of Health promoted the initiative "Okkio alla SALUTE" in primary schools, which was the first national survey to estimate the prevalence of overweight and obese children, and gathered information about diet, physical activity and the role of families and schools. Data presented in 2008 and later in 2010, 2012 and 2014, denounced the high rates of obesity and overweight, particularly in southern regions, where values exceeded $40 \%$. It is favored by physical inactivity, an unhealthy diet and parents with a low educational attainment level, who were often found to have no real idea about their children's 4 appearance [18-20]. The 2014 data showed an increased involvement of schools in education on correct lifestyles, but the persistence of bad eating habits, which produced only a slight improvement on 2008 values [21]. This study examined the lifestyle and body composition of children aged between 8 and 10 years in Marcianise, a small town in Campania, the region with the highest percentage of childhood corpulence and obesity, to detect possible behavioral mistakes and potential repercussions on the body.

\section{Materials and Methods}

In this study were enrolled 272 children (131 $\mathrm{M}$ and $141 \mathrm{~F})$ attending classes IV and V of two primary schools in Marcianise, a small Italian town in the Campania region.

Each subject had a normal physical examination and met the following inclusion criteria: no medication or nutritional supplements with the exception of vitamins, and minerals.

The parents of participants were provided with both written and oral information regarding the study protocol and were ensured that they were free to withdraw from the study at any time. All subjects gave their written informed consent before participation. All procedures conformed to the directives of the Declaration of Helsinki. The study was approved by the Human Ethical Review Committee of Second University of Naples.

Body weight and height were measured using standard techniques. The BMI was calculated as body weight/square of height $\left(\mathrm{kg} / \mathrm{m}^{-2}\right)$. Body composition was determined by conventional Body Impedance Analysis (BIA) with a single-frequency $(50 \mathrm{kHz})$ bioelectrical impedance analyzer (BIA 101 RJL, Akern Bioresearch, Firenze, Italy), according to thestandard tetrapolar technique, with the subject in supine position and the electrodes placed on the dorsal surface of right foot and ankle, and right wrist and hand. Subjects were asked to refrain from strenuous exercise during the 3 days preceding the measurements. After overnight fasting, they were invited to empty the bladder before being evaluated; furthermore they did not have to drink four hours before undergoing the examination. Body composition was then calculated by bioelectrical measurements and anthropometric data using the software provided by the manufacturer, which incorporated validated predictive equations for total body water, fat mass and fat free mass [22-24].

All parents completed a self-assessment questionnaire that investigated routine for eating (frequency of intake of different foods and the type and number of meals made during the day), physical exercise (type and frequency of sport) and lifestyles (hours before TV and video games, frequency of playing outdoors, means of transport to get to school) of their children. In addition, the questionnaire investigated the possible presence of family members who were overweight or obese, the parent's physical activities, and their perception of their child's body shape [25].

\section{Statistical analysis}

The R Project for Statistical Computing software (version 3.1.0) was used for statistical analyses. Means and SDs were calculated for each of the analyzed variables and statistical significance was set at $\mathrm{p} \leq 0.05$. The Shapiro-Wilk test was used to verify the normal distribution of variables. The significance of the data was verified by the Student's Ttest.

\section{Results}

The body mass index was compared with SIEDP-2006 [26] growth charts. The $32 \%$ of children ( $38 \%$ M $27 \%$ F) were overweight with a BMI between the 85th and 97th percentile, and 19\% (22\% M 16\% F) were obese with a BMI above the 97th percentile. In the first group, the fat mass measured with BIA constituted $40 \%$ of body weight (M 39\% and F 41\%), whilst in the second it constituted $48 \%$ (Figures 1 and 2).

The parental perception was very different from reality, as according to them, only $18 \%$ of the children were overweight and $7 \%$ obese (Figure 3). Only $30 \%$ of parents took part in sports; whilst amongst the children, $52 \%$ of females and $64 \%$ of males took part in sporting activities 2-3 times a week. The most popular sports were football (30\%), boxing (25\%) and swimming (17\%) for males and dancing (53\%), swimming (16\%) and volleyball (15\%) for females (Figure 4).

There were significant differences in lifestyle and eating habits between males and females. The children spent two hours per day watching TV, and videogames were found to be the dominant form of entertainment. $71 \%$ went to school by car, although the average distance was equal to $1.4 \mathrm{~km}$. This decreased to $400 \mathrm{~m}$ in $25 \%$ of pupils who went on foot. $90 \%$ of children had breakfast and in $74 \%$ of cases, this was found to be milk. It was taken with biscuits or cereals in $40 \%$ and $18 \%$ of cases, respectively (Figure 5).

At school, only 5\% ate healthy foods like fruit or yoghurt, but they preferred sandwiches (45\%) and cakes (33\%) (Figure 6). Although in the afternoon, the percentage of children eating fruit or yogurt increased to $33 \%, 45 \%$ preferred cakes, sandwiches or cookies (Figure 7). The $18 \%$ of children did not eat vegetables, $43 \%$ eating them once a day and $41 \%$ twice a day. $61 \%$ of children did not eat fruit, $19 \%$ eating it once a day and $20 \%$ twice a day (Figure 8 ). At lunch, pasta was the predominant food $(97 \%)$, mostly with sauce or with vegetables (2 times per week), followed by rice (1 time per week) and pasta with vegetables (every 10 days), whilst the average intake of minestrone or soups dropped dramatically to 2 times a month. At lunch, $63 \%$ had a second helping, and $27 \%$ ate bread. Only $8 \%$ ate pasta for dinner, whilst the main course was the predominant food (95\%), taken with bread in $61 \%$ of cases. Amongst the main courses, white meat and sausages were eaten most frequently ( 2 times per week), followed by red meat, cheese and eggs ( 1 time per week), then pork and fish (every 10 days). On average, the children ate pizza and/or sandwiches as fast food once a week, and carbonate and sweet drinks 3 times a week (Figure 9). The average daily intake of bread amounted to $80 \mathrm{~g}$, and that of water was 1 liter. 
Citation: Piombino L, Messina A, Piombino L, Monda V, Moscatelli F, et al. (2016) An Assessment of Body Composition and Lifestyle in Children Aged from 8 to 10 years. Biol Med (Aligarh) 8: 298. doi:10.4172/0974-8369.1000298

Page 3 of 5

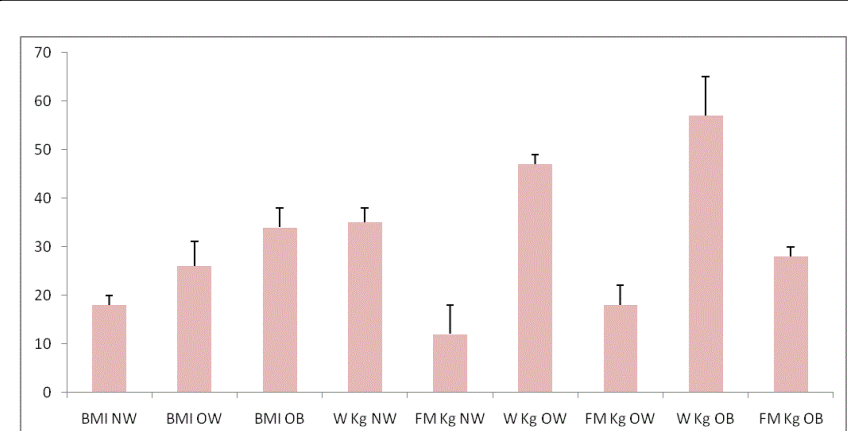

Figure 1: Mean and standard deviation of Body mass index (BMI), weight $(\mathrm{W})$, and fat mass (FM) in normal-weight (NW), overweight (OW) and obese female children.

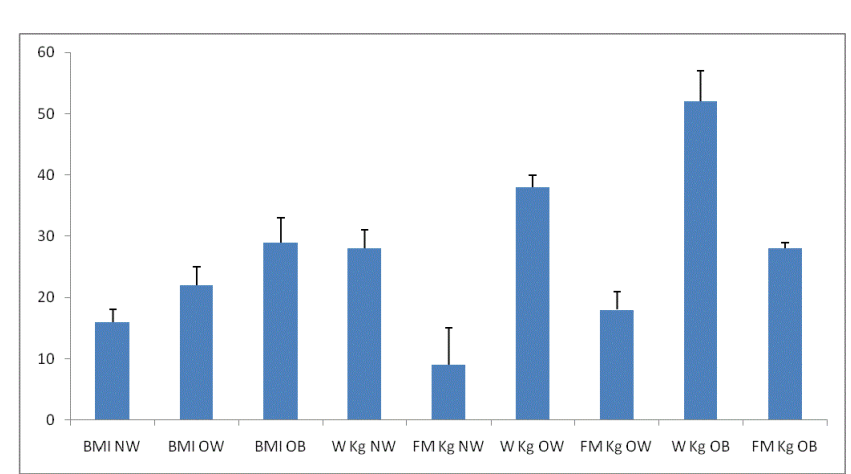

Figure 2: Mean and standard deviation of Body mass index (BMI), weight $(\mathrm{W})$, and fat mass $(\mathrm{FM})$ in normal-weight $(\mathrm{NW})$, overweight $(\mathrm{OW})$ and obese male children.

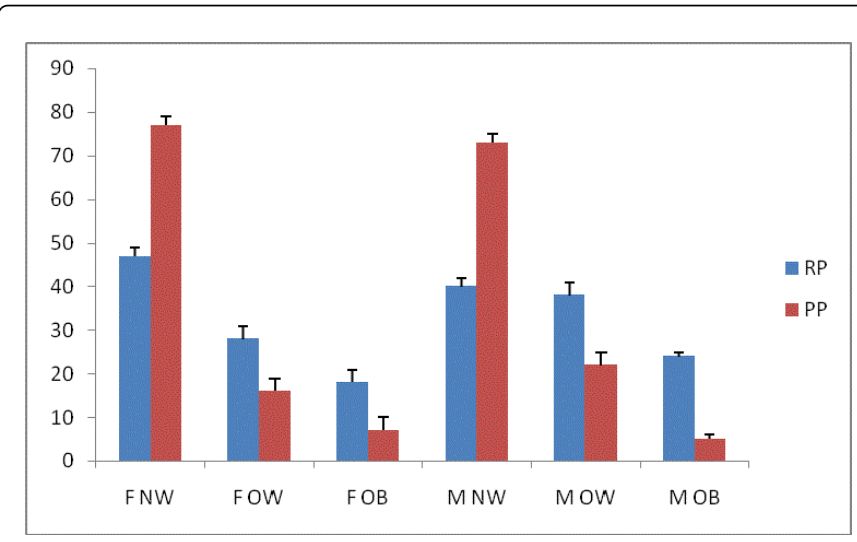

Figure 3: Differences (men and standard deviation) between the real percentage (RP), and the parental perception (PP), of female normal-weight (F NW), female over-weight (F OW), female obese (F OB), male normal-weight (M NW), male over-weight (M OW), male obese (M OB).

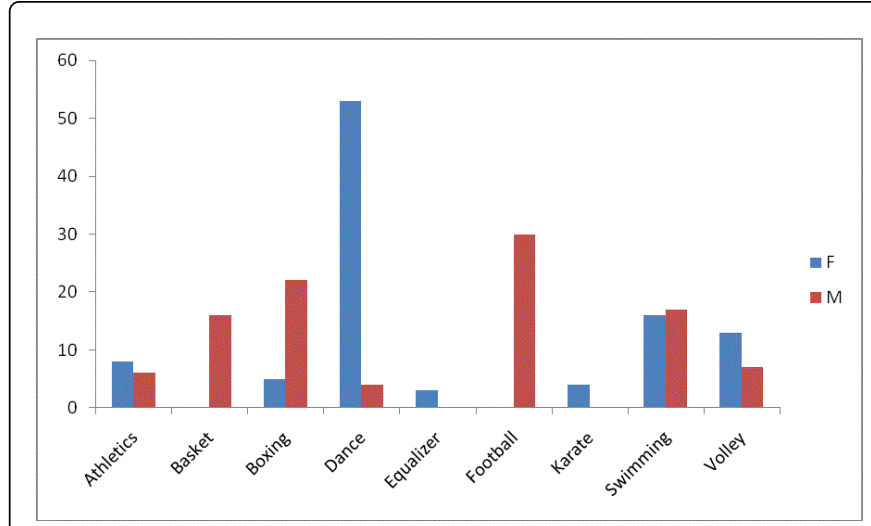

Figure 4: Kind of sport practiced by the $52 \%$ of the females and by the $64 \%$ of males.

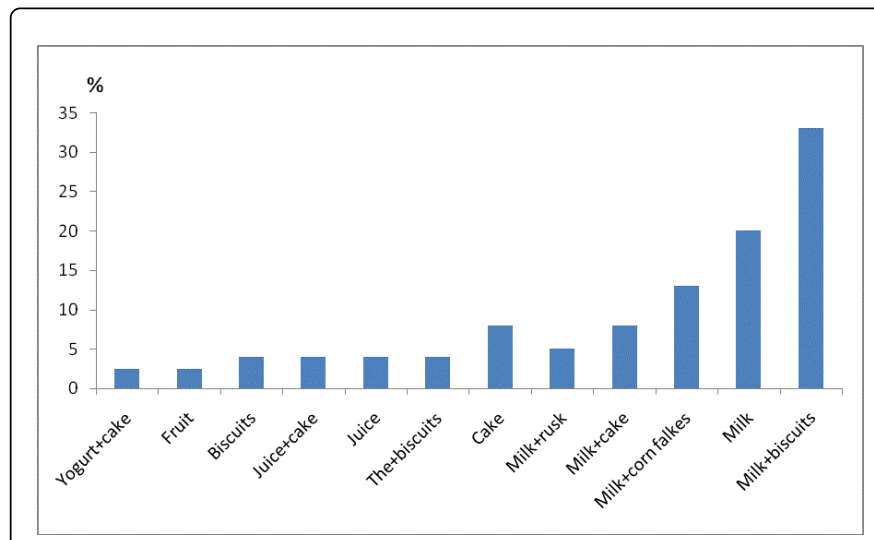

Figure 5: Breakfast intake in percentage.

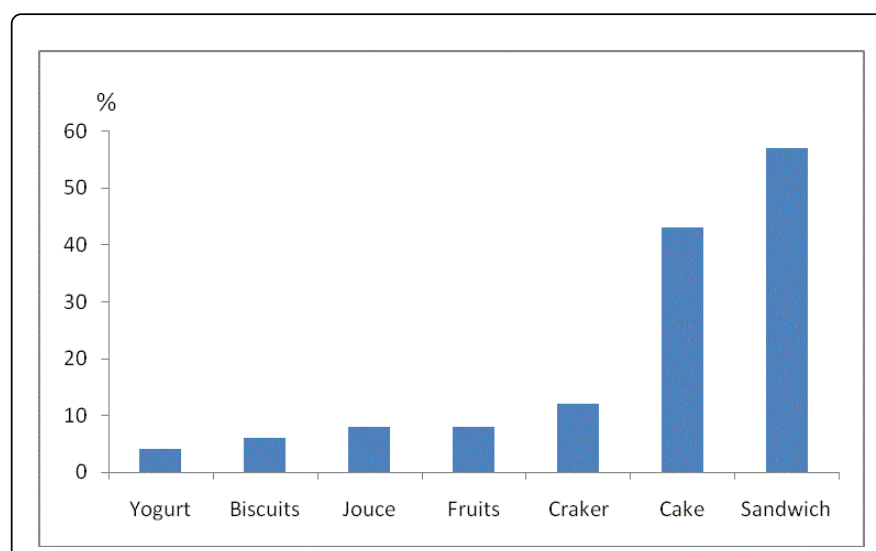

Figure 6: The mid-morning snack intake in percentage. 


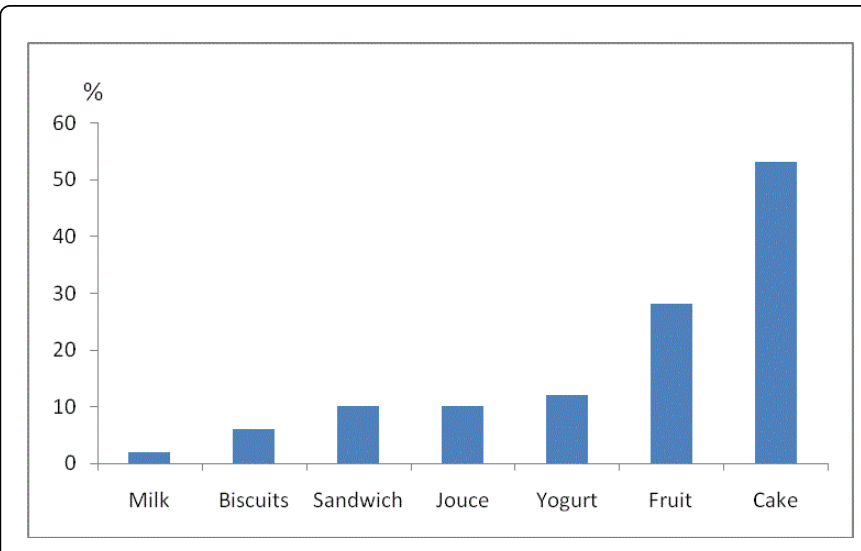

Figure 7: Mid-afternoon snack intake in percentage.

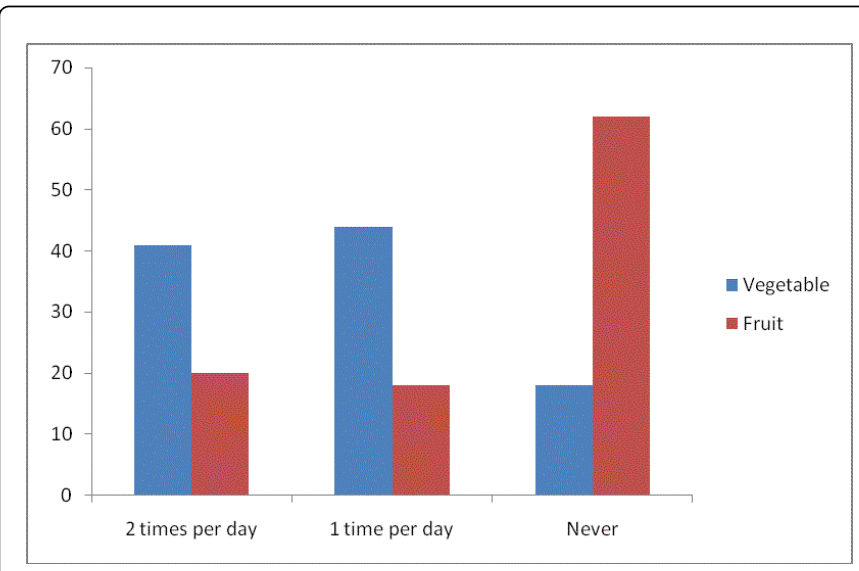

Figure 8: The percentage of intake of vegetable and fruit.

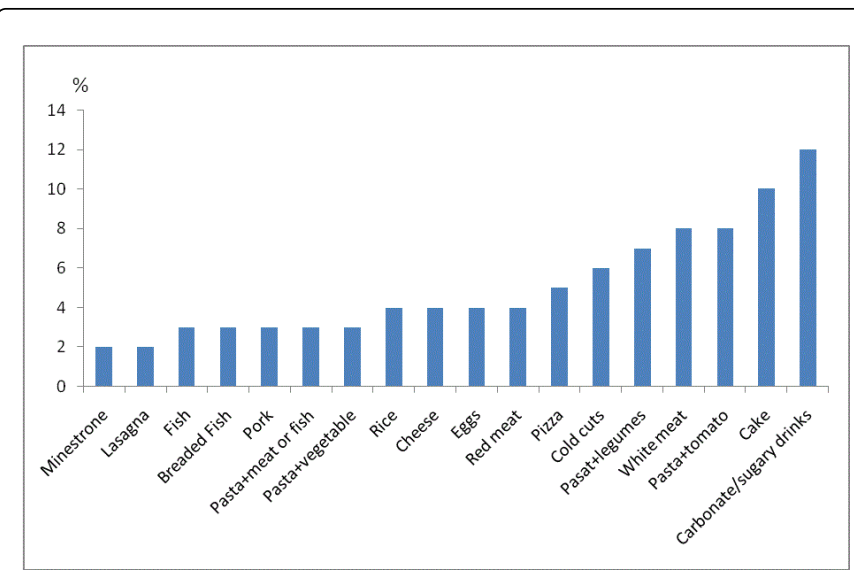

Figure 9: Monthly frequency of intake of the most eaten dishes.

\section{Discussion}

If the highest number of overweight males are excluded, BMI calculated were in line with those reported in 2014 by the Italian
Ministry of Health. However, the BIA revealed however, quite alarming fat mass values, probably correlated to a greater differentiation of totipotent cells into adipocytes, which occurs when excessive food intake happens during the growth phase. The questionnaire administered disclosed the fact that sedentary behaviour was associated with the frequent intake of high calorie foods. Children did not eat enough fruits and fish, while the amounts of meats, sweets, soft drinks and bread was excessive. 3 out of 4 children examined brought high energy foods to school, which were high in sugar, salt and added fats, and the same was true of their mid-afternoon snacks. Children were also found to walk too little, spend too much time watching TV and preferred videogames to playing outdoors. Despite the efforts of schools to educate their pupils towards a healthier lifestyle, bad eating habits persist. And this is a problem that concerns the whole of Europe, where the primary prevention program promoted for two years by the IDEFICS was unsuccessful [27-29]. A recent review [30] confirmed this observation, demonstrating low intakes of fruits and vegetables in most American, European and Australian studies, between 2 and 3 portions per day which are well below the recommended five portions. This target value of five portions should consider the age of the child, that is, the appropriate amount of fruits and vegetables depends on the energy needs, where for example, a young child should eat more than $200 \mathrm{~g}$ per day [31]. The fact that $44 \%$ of children who are overweight, and $63 \%$ of those who are obese are perceived as normal by their parents shows that the root of the failure was insufficient awareness of the problem within the family, resulting in insufficient collaboration in the program to re-educate their children toward a healthier lifestyle [26,32-35]. We therefore stress that activating direct intervention plans with families is a basic condition to reduce the high incidence of obesity and related diseases.

Several lifestyle factors are described as behavioural contributors to childhood obesity [36-38], which are often associated with each other. Regarding intervention targets, the literature typically deals separately with these factors. The advantage of combining the most important lifestyle factors in a compliance score may provide a more holistic view: complying with certain aspects of lifestyle message to improve the quality of family life and the newly developed quality of life score has not been directly shown. But as the quality of life score used in this paper contains a module characterising the quality of family relations, we are quite confident that its use is valid for indicating the key message with respect to an improved quality of family life. The compliance of young children to health-behaviour recommendations was very low and should therefore be improved, preferably via those actors who can serve as a role model, mediator for the different lifestyle aspects or nutritional gate-keeper for the children.

\section{References}

1. Borrello M, Pietrabissa G, Ceccarini M, Manzoni GM, Castelnuovo G (2015) Motivational Interviewing in Childhood Obesity Treatment. Front Psychol 6: 1732.

2. Esposito M, Serpe FP, Diletti G, Messina G, Scortichini G, et al. (2014) Serum levels of polychlorinated dibenzo-p-dioxins, polychlorinated dibenzofurans and polychlorinated biphenyls in a population living in the Naples area, southern Italy. Chemosphere 94: 62-69.

3. Aristizabal JC, Barona J, Hoyos M, Ruiz M, Marin C (2015) Association between anthropometric indices and cardiometabolic risk factors in preschool children. BMC Pediatr 15: 170.

4. Kozakova M, Morizzo C, Bianchi V, Marchetti S, Federico G, et al. (2016) Hemodynamic overload and intra-abdominal adiposity in obese children: Relationships with cardiovascular structure and function. Nutr Metab Cardiovasc Dis 26: 60-6. 
5. Marcovecchio ML, Gravina M, Gallina S, et al. (2016) Increased left atrial size in obese children and its association with insulin resistance: a pilot study. Eur J Pediatr 175: 121-130.

6. Manco M, Grugni G, Di Pietro M, Balsamo A, Di Candia S, et al. (2015) Triglycerides-to-HDL cholesterol ratio as screening tool for impaired glucose tolerance in obese children and adolescents. Acta Diabetol 15: $1-6$.

7. Topcu S, Orhon FS, Tayfun M, Ucakturk SA, Demirel F (2016) Anxiety, depression and self-esteem levels in obese children: a case-control study. J Pediatr Endocrinol Metab 29: 357-361.

8. Lim CS, Espil FM, Viana AG, Janicke DM (2015) Associations Between Anxiety Symptoms and Child and Family Factors in Pediatric Obesity. J Dev Behav Pediatr 36: 664-672.

9. Bacchini D, Licenziati MR, Garrasi A, Corciulo N, Driul D, et al. (2015) Bullying and Victimization in Overweight and Obese Outpatient Children and Adolescents: An Italian Multicentric Study. PLoS One 10: e0142715.

10. Ahrens W, Bammann K, Siani A, Buchecker K, De Henauw S, et al. (2011) The IDEFICS cohort: design, characteristics and participation in the baseline survey. Int J Obes (Lond) 35 Suppl 1: S3-15.

11. Ahrens W, Pigeot I, Pohlabeln H, De Henauw S, Lissner L, et al. (2014) Prevalence of overweight and obesity in European children below the age of 10. Int J Obes (Lond) 38 Suppl 2: S99-107.

12. Fernandez-Alvira JM, Bornhorst C, Bammann K, Gwozdz W, Krogh V, et al. (2015) Prospective associations between socio-economic status and dietary patterns in European children: the Identification and Prevention of Dietary- and Lifestyle-induced Health Effects in Children and Infants (IDEFICS) Study. Br J Nutr 113: 517-25.

13. Lanfer A, Knof K, Barba G, Veidebaum T, Papoutsou S, et al. (2012) Taste preferences in association with dietary habits and weight status in European children: results from the IDEFICS study. Int J Obes (Lond) 36: 27-34.

14. Santaliestra-Pasías AM, Mouratidou T, Reisch L, Pigeot I, Ahrens W, et al. (2015) Clustering of lifestyle behaviours and relation to body composition in European children. The IDEFICS study. Eur J Clin Nutr 69: 811-816

15. Konstabel K, Veidebaum T, Verbestel V, Moreno LA, Bammann K, et al. (2014) Objectively measured physical activity in European children: the IDEFICS study. Int J Obes (Lond) 38 Suppl 2: S135-143.

16. Buck C, Kneib T, Tkaczick T, Konstabel K, Pigeot I (2015) Assessing opportunities for physical activity in the built environment of children: interrelation between kernel density and neighborhood scale. Int J Health Geogr 14: 35.

17. Guberti E, Alonzo E, Cairella G, Pontieri V, Talarico F (2015) From surveillance to development of nutritional guidelines. Epidemiol Prev 39: 66-70.

18. Lazzeri G, Pammolli A, Pilato V, Giacchi MV (2011) Relationship between 8/9-yr-old school children BMI, parents' BMI and educational level: a cross sectional survey. Nutr J 10: 76.

19. Regber S, Novak M, Eiben G, Bammann K, De Henauw S, et al. (2013) Parental perceptions of and concerns about child's body weight in eight European countries - the IDEFICS study. Pediatr Obes 8: 118-129.

20. Bozzola M, Bozzola E, Abela S, Amato S (2012) Childhood obesity: know it to prevent it. Ig Sanita Pubbl 68: 473-482.

21. Lauria L, Spinelli A, Nardone P, Buoncristiano M, Bucciarelli M, et al. (2015) Unhealthy eating habits among children aged 8-9 are still common in Italy. Epidemiol Prev 39: 139.

22. Hauschild DB, Barbosa E, Moreira EA, Ludwig Neto N, Platt VB, et al. (2016) Nutrition Status Parameters and Hydration Status by Bioelectrica
Impedance Vector Analysis Were Associated With Lung Function Impairment in Children and Adolescents With Cystic Fibrosis. Nutr Clin Pract pii: 0884533615627157 . [Epub ahead of print]

23. Monda M, Messina G, Mangoni C, De Luca B (2008) Resting energy expenditure and fat-free mass do not decline during aging in severely obese women. Clin Nutr 27: 657-659.

24. Triggiani AI, Valenzano A, Ciliberti MA, Moscatelli F, et al. (2015) Heart rate variability is reduced in underweight and overweight healthy adult women. Clin Physiol Funct Imaging .

25. Mensink GB, Burger M (2004) What do you eat? Food frequency questionnaire for children and adolescents.Bundesgesundheitsblatt Gesundheitsforschung Gesundheitsschutz 47: 219-26.

26. Cacciari E, Milani S, Balsamo A, Spada E, Bona G, et al. (2006) Italian cross-sectional growth charts for height, weight and BMI (2 to $20 \mathrm{yr}$ ). J Endocrinol Invest 29: 581-593.

27. Baranowski T, Lytle L (2015) Should the IDEFICS outcomes have been expected? Obes Rev 16 Suppl 2: 162-172.

28. De Henauw S, Verbestel V, Marild S, Barba G, Bammann K, et al. (2011) The IDEFICS community-oriented intervention programme: a new model for childhood obesity prevention in Europe? Int J Obes (Lond) 35 Suppl 1: S16-S23.

29. Kovács E, Siani A, Konstabel K, Hadjigeorgiou C, de Bourdeaudhuij I, et al. (2014) Adherence to the obesity-related lifestyle intervention targets in the IDEFICS study. Int J Obes (Lond) 38: S144-51.

30. Evans CE, Christian MS, Cleghorn CL, Greenwood DC, Cade JE (2012) Systematic review and meta-analysis of school-based interventions to improve daily fruit and vegetable intake in children aged 5 to $12 \mathrm{y}$. Am J Clin Nutr 96: 889-901.

31. Serra-Majem L, MacLean D, Ribas L, Brule D, Sekula W, et al. (2003) Comparative analysis of nutrition data from national, household, and individual levels: results from a WHO-CINDI collaborative project in Canada, Finland, Poland, and Spain. J Epidemiol Community Health 57: 74-80.

32. Monda M, Messina G, Scognamiglio I, Lombardi A, Martin GA, et al. (2014) Short-term diet and moderate exercise in young overweight men modulate cardiocyte and hepatocarcinoma survival by oxidative stress. Oxid Med Cell Longev 131024.

33. Di Bernardo G, Messina G, Capasso S, Del Gaudio S, Cipollaro M, et al. (2014) Sera of overweight people promote in vitro adipocyte differentiation of bone marrow stromal cells. Stem Cell Res Ther 5: 4 .

34. Messina G, Vicidomini C, Viggiano A, Tafuri D, Cozza V, et al. (2012) Enhanced parasympathetic activity of sportive women is paradoxically associated to enhanced resting energy expenditure. Auton Neurosci 169: 102-6.

35. Viggiano A, Viggiano E, Di Costanzo A, Viggiano A, Andreozzi E, et al. (2015) Kaledo, a board game for nutrition education of children and adolescents at school: cluster randomized controlled trial of healthy lifestyle promotion. Eur J Pediatr 174: 217-28.

36. Messina G, De Luca V, Viggiano A, Ascione A, Iannaccone T, et al. (2013) Autonomic nervous system in the control of energy balance and body weight: personal contributions. Neurol Res Int 2013: 639280.

37. Amaro S, Viggiano A, Di Costanzo A, Madeo I, Viggiano A, et al. (2006) Kalèdo, a new educational board-game, gives nutritional rudiments and encourages healthy eating in children: a pilot cluster randomized trial. Eur J Pediatr 165: 630-635.

38. Sherry B (2005) Food behaviors and other strategies to prevent and treat pediatric overweight. Int J Obes (Lond) 29 Suppl 2: S116-126. 